\title{
Is social stress in the first half of life detrimental to later physical and mental health in both men and women?
}

\author{
Nardi Steverink • René Veenstra • \\ Albertine J. Oldehinkel · Rijk O. B. Gans • \\ Judith G. M. Rosmalen
}

Published online: 11 February 2011

(C) The Author(s) 2011. This article is published with open access at Springerlink.com

\begin{abstract}
This study examined gender differences in the associations between affection- and status-related stressors encountered in the first half of life and physical and mental health problems later on. Based on the theory of Social Production Functions (SPF) two hypotheses have been formulated, which were tested in a representative sample of 446 men and 514 women (aged 40-79). Main outcome measures were number of chronic somatic diseases and level of psychological distress. As expected, regression
\end{abstract}

Communicated by H.-W. Wahl.

\section{N. Steverink $(\bowtie)$}

Section Health Psychology, Department of Health Sciences, University Medical Center Groningen, University of Groningen, P.O. Box 196, 9700 AD Groningen, The Netherlands

e-mail: b.j.m.steverink@med.umcg.nl

N. Steverink $\cdot$ R. Veenstra

Department of Sociology, University of Groningen, Groningen,

The Netherlands

R. Veenstra

Department of Psychology, University of Turku,

Turku, Finland

\section{A. J. Oldehinkel}

Interdisciplinary Center for Psychiatric Epidemiology, University Medical Center Groningen, University of Groningen, Groningen, The Netherlands

\section{R. O. B. Gans}

Department of Internal Medicine, University Medical Center

Groningen, University of Groningen, Groningen,

The Netherlands

J. G. M. Rosmalen

Department of Psychiatry, University Medical Center

Groningen, University of Groningen, Groningen,

The Netherlands analyses showed no gender differences in the associations between affection-related stressors and physical and mental health problems later on. In contrast, but as also expected, status-related stressors encountered in the first half of life were associated with later physical and mental health for men only. It is concluded that the gender differences in the associations between earlier social stressors and later health problems may be more complex than the common assumption that men are only affected by status stress and women only by affection stress. This study contributes to the knowledge on gender differences concerning the link between social stress and health, and it indicates that social experiences encountered earlier in life are of importance for being healthy and happy in later life.

Keywords Social stressors - Gender - Social production function theory · Chronic somatic diseases · Psychological distress

\section{Introduction}

It is widely recognized that social relationships play an important role in the achievement and maintenance of physical and mental health. Positive social relationships are associated with better psychological well-being and physical health, including survival (Litwin 2007; Seeman 1996). Conversely, social isolation and negative social experiences are harmful for physical and mental health (Cacioppo et al. 2006; Hawkley et al. 2010; House et al. 1988; Newsom et al. 2008; Uchino et al. 1996).

Despite this sizable literature, the issue of gender differences in the associations between social stress and health is not well understood. An important reason for this may be the fact that the theoretical basis that may explain 
the gender differences is still unsettled. In this study, we therefore, aim to contribute to solving this problem by using the theoretical framework of Social Production Function (SPF) theory (Lindenberg 1996; Ormel et al. 1999; Steverink and Lindenberg 2006). SPF theory may help to integrate existing findings, and, additionally, help to understand the gender differences. SPF theory approaches the health consequences of social stressors from the viewpoint of deprivations in the fulfillment of basic human social needs. If basic need fulfillment fails to occur (which causes stress), the necessary conditions for effective functioning and well-being are lacking, and health problems may follow (cf., Deci and Ryan 2000). Two basic human social needs that are considered in SPF theory are especially important here: the needs for affection and status.

The need for affection (i.e., feel emotionally close to others and be loved and cared for) is generally fulfilled by close personal relationships such as parents, family, and spouses. Stress as a result of negative experiences concerning these social relationships, therefore, is seen in SPF theory as stress related to the fulfillment of the need for affection.

The need for status (i.e., the need to be approved because of one's relative social position or of certain achievements) is largely fulfilled in social situations such as school and work. Therefore, stress as a result of negative experiences in these social settings is seen, in SPF theory, as stress related to the fulfillment of the need for status.

Many of the social stressors that are considered in the existing literature on social stress and health closely relate to these kinds of affection- and status-related stressors. Indeed, especially social stressors related to personal relationships, and to work and subjective relative rank were found to be detrimental to health (cf. Cohen et al. 1998, 2008).

With regard to the literature on gender differences, it is often shown that women suffer more from stressors in the personal relational domain (i.e., affection-related stress), whereas men suffer more from stressors in the social ranking domain (i.e., status-related stress). For example, women were found to be more sensitive to relational conflict in terms of endocrine function than men (KiecoltGlaser et al. 1996). Men showed greater cortisol responses to achievement challenges and women showed greater responses to social rejection challenges (Stroud et al. 2002). Oldehinkel et al. (2007) found that, among early adolescent boys and girls, experiences in the achievement domain (i.e., not being good at sports) were predictive of depression for boys, and experiences in the interpersonal domain (i.e., not being liked) were predictive of depression for girls. With respect to status-related stress, some studies showed a stronger association between work-related stress (e.g., job strain and downward socioeconomic mobility) and distress among men than among women (e.g., McDonough and Walters 2001; Tiffin et al. 2005; Vermeulen and Mustard 2000). Hammarström and Janlert (2002) found that early unemployment was, over a period of 14 years, related to more somatic symptoms in men, and to more psychological symptoms in both men and women.

Still, also a number of inconsistent findings have been reported with respect to gender. For example, no gender differences were found in the rate of wound healing following marital conflict (Kiecolt-Glaser et al. 2005), nor in the associations of strained relationships with psychological distress (Umberson et al. 1996) or with chronic conditions (McDonough and Walters 2001). In addition, it was found that relationship stress related to poorer physical and mental health for men only (Denton et al. 2004; Levenson et al. 1994), whereas Denton et al. (2004) found job strain to be negatively associated with distress for women.

In sum, many of the studies just mentioned fit in with the idea of affection- and status-related stress and their health consequences. In addition, many studies also fit in with a general notion on gender-specific social orientations, which states that men are more status-oriented, whereas women are more affection-oriented (e.g., Cross and Madson 1997; Cyranowski et al. 2000). According to the latter idea, women would suffer especially from affection-related stress, whereas men would suffer more from status-related stress. Still, as said, these gender-specific effects are not consistently found, and sometimes findings are even opposite. In addition, studies outside the health field suggest that both men and women care for affection and belongingness (e.g., Baumeister and Leary 1995; Pendell 2002). The latter may indicate that, at least, affectionrelated stress may also be detrimental to the health of men, not only of women.

SPF theory may be of help here, because it states that, basically, both men and women have a need for affection and status and, therefore, will suffer from stress in both of these need fulfillments. However, SPF theory also assumes a gender-specificity in possibilities for substitution or compensation between different need fulfillments (Steverink et al. 1998), which may help to explain the gender differences. Substitution between different need fulfillments means that people will switch to increased efforts to achieve more of another social need fulfillment, when a certain social need fulfillment is blocked or lost. In general, people will try to compensate a lack in status fulfillment by increasing efforts to 'produce' affection. This is due to the fact that, in general, affection need fulfillment is relatively 'easier' than status need fulfillment. If one already 'produces' affection, it does not take many additional efforts to be kind to another person and be caring. Status, on the other hand, is a positional 'good', and therefore is it not very easy to increase its production if affection need 
fulfillment is difficult. It requires something special, such as specific talents, skills or assets. Therefore, in general, it will be relatively easier to compensate loss of status by more affection need fulfillment than loss of affection by more status. Indications for this mechanism have been found in studies on SPF theory (Nieboer and Lindenberg 2002; Steverink 2001; Steverink and Lindenberg 2006), but also elsewhere. For example, Artazcoz et al. (2004) found that women had less negative mental health effects of unemployment (status) if they had children in the home (affection).

Important for understanding the gender differences in social stress and health outcomes is that, in the process of substituting lack of status by increased affection, women have an important advantage over men: both men and women will try to increase affection, but for women-as compared to men-it is relatively 'easier' to do so. Women are not only more socialized than men to give and receive affection (Maccoby 1990), they also seem to be better 'hard-wired' (physiologically) for giving and receiving attachment and connectedness, due to, among others, oxytocine secretion, which occurs especially in females and stimulates prosocial contacts (cf., Taylor et al. 2002). Therefore, when stress is encountered in the domains of status or affection need fulfillment, both men and women will suffer from this. However, women will suffer less from status-related stress than men because women can compensate this relatively easier than men with increased affection need fulfillment. Thus, it is hypothesized that status-related stress will be less detrimental to the health of women than to men's health. Affection-related stress, however, will be detrimental to both men's and women's health. These two hypotheses will be tested in the following. We selected men and women of age 40-79, and investigated the associations of the social stressors they had encountered before the age of 40 (from birth on), with physical and mental health problems later on (after the age of 40). We chose to focus on age 40, because, in general, health problems start to occur when people are in their mid forties (Bruggink et al. 2010), women even some years earlier than men (Oksuzyan et al. 2010). Moreover, indications exist for longer term health effects of negative social experiences suffered earlier in life (e.g., Luecken et al. 2006; Repetti et al. 2002; Tiffin et al. 2005).

\section{Methods}

\section{Study population}

Our study has been performed in a sub study of the PREVEND study (Prevention of REnal and Vascular ENd stage Disease), a population cohort study running since 1997 in the city of Groningen, the Netherlands. As a primary objective, PREVEND investigates microalbuminuria as a risk factor for renal and cardiovascular disease. Details of the PREVEND study protocol have been described elsewhere (Pinto-Sietsma et al. 2000). The total screening program in 1997-1998 was completed by 8,592 subjects (aged 28-75 years), which were again invited to visit the outpatient clinic in 2001-2003. Out of the 6,894 subjects (80.2\% of the actual study cohort in 1997-1998) that completed the follow-up program, a population representative sample of 2,554 participants was invited for additional measurements on psychosocial determinants and outcomes of health, constituting the initial sample of the sub study. Of the 2,554 participants, 1,094 completed the additional measurements, $46.3 \%$ male $(N=506)$, with an average age of 53.1 years ( $\mathrm{SD}=11.4$; range $33-79$ ). PREVEND participants who did or did not participate in the sub study did not significantly differ concerning age $(t=0.79, \quad P=0.43)$, and gender $\left(\chi^{2}(1, N=\right.$ $2554)=1.75, P=0.19]$. The study was approved by the medical ethics committee and was conducted in accordance with the guidelines of the declaration of Helsinki. Written informed consent was obtained from all participants.

The sub study sample consisted of people aged 33-79, but because we were interested in people in their second half of life (having experienced social stress in their first half of life), we selected the participants of age 40 and older $(N=960)$. This subsample contained $446(46.5 \%)$ men and $514(53.5 \%)$ women. Mean age was 55.4 $(\mathrm{SD}=10.1$; range $40-79)$.

\section{Measures}

\section{Physical health problems}

Physical health problems were measured by asking respondents to complete a checklist of 22 chronic somatic diseases, by indicating whether they had suffered (yes or no) from each disease in the preceding year. Examples are: lung disease (e.g., asthma, COPD), gallstones, rheumatoid disease, osteoarthritis, and bowel disorder. Four common chronic somatic diseases were not included in the checklist (i.e., diabetes, CHD, CVA and hypertension), because these had been already asked at the first measurement of the PREVEND study in 1997-1998. If participants had indicated to have one or more of these four chronic diseases in 1997-1998, these scores were added to the scores on the checklist of 22 . If one or more of these four diseases had developed after the measurement of 1997-1998, they most likely popped up in the three open questions that participants could fill out on possible other chronic somatic diseases that were not in the checklist of the 22 chronic somatic diseases. If people reported on one or more other 
chronic somatic diseases, these were analyzed separately and counted if they indeed could be considered a chronic somatic disease (e.g., prostate disease). The actual range of chronic somatic diseases was 0-10: 416 participants (43.3\%) mentioned 0 diseases, $434(45.3 \%)$ had 1 or 2 chronic diseases, $60(6.2 \%)$ persons had 4-7 chronic diseases, and 3 participants mentioned 8, 9, or 10 diseases.

\section{Mental health problems}

Participants completed the Dutch translation of the 12-item General Health Questionnaire (GHQ-12) measuring current psychological distress (Koeter 1992) at home before the visit to the outpatient clinic. The GHQ-12 comprises 12 questions dealing with two major classes of phenomena: inability to continue to carry out one's normal healthy functions (e.g., playing a useful part in things, able to enjoy day-to-day activities) and the appearance of new phenomena of a distressing nature (e.g., losing sleep over worry, thinking of yourself as worthless). Respondent were asked whether they had recently experienced a particular symptom or item of behavior on a scale ranging from 'less than usual' to 'much more than usual'. The internal consistency (Cronbach's $\alpha$ ) in the present sample was 0.86 . The here reported analyses are based on a GHQ sum score that was calculated using the Likert GHQ scoring method $(0-1-2-3)$. Average item score was $0.94 \quad(\mathrm{SD}=0.48$; range $0-3)$.

\section{Affection- and status-related stressors}

The affection- and status-related stressors were measured by a selection of items of two existing questionnaires, i.e., the List of Threatening Experiences (LTE) and the List of Long-term Difficulties (LLD). The LTE (Brugha and Cragg 1990), asking participants whether or not 12 adverse life-events took place in the previous year, was modified by adding questions about the occurrence of life-events in three life periods: 0-12 years (childhood), 13-18 years (adolescence), and 19-39 years (adulthood). The LLD is a modified version of the Groninger Lijst Langdurige Moeilijkheden (GLLM), which in its turn originates from the Mooney Problem Checklist (Gordon 1949). Participants were asked whether or not they experienced 12 possible chronic difficulties (e.g., marital problems) in the previous year. The same age categories (as described for the LTE) were added. Participants were also asked to rate the stressfulness of a chronic difficulty in the period in which the chronic difficulty was present on a three point rating scale: not stressful, moderately stressful, or highly stressful.

The three questions that were asked for the occurrence of affection-related stressors in childhood (age 0-12) were:
"Have you, as a child (i.e., before the age of 12) been separated from your mother for more than 3 months?"; "Has a parent, (child), brother, sister (or partner) died, when you were 0-12 years of age?"; "Did you have difficulties with your parents (e.g., conflicts regularly, nonacceptance) at the age of 0-12?". Two questions were asked for affection-related stressors in adolescence (age 13-18): "Has a parent, (child), brother, sister (or partner) died, when you were 13-18 years of age?"; "Did you have difficulties with your parents (e.g., conflicts regularly, nonacceptance) at the age of 13-18?". Three questions were asked for affection-related stressors in adulthood (age 19-39): "Did you and your partner separate when you were 19-39 years of age?"; "Did you have difficulties in your partner relation (e.g., jealousy, conflicts, doubts, quarrel) at the age of 19-39?"; "Did you have difficulties in the relationship with your parents? (e.g., conflicts regularly, non-acceptance) at the age of 19-39?".

Status-related stressors were also measured for the same three life periods. One question was asked for status-related stress in childhood: "How stressful was school/study (e.g., too demanding, not to combine with other duties) when you were $0-12$ years of age?" One question was asked for status-related stress in adolescence: "How stressful was school/study (e.g., too demanding, not to combine with other duties) when you were 13-18 years of age?" Two questions were asked for status-related stressors in adulthood: "Did you become jobless and not succeed in finding work again at the age of 19-39?"; "How stressful was your work (e.g., conflicts, too demanding, threat of dismissal) when you were 19-39 years of age?".

In order to balance the different answer categories and the different number of items for the age periods, the scores of the items with three answer categories were dichotomized into $0=$ no, $1=$ a bit or much. We decide to do so because the category much turned out to be used by only a very small percentage (average of less than $8 \%$ ) of the respondents. Next, the mean score for the total affectionrelated stress and total status-related stress was calculated by summing up the individual (dichotomized) item scores and dividing it by the total number of items for each kind of stress.

Note that the data on the social stressors were not collected with the precise objective of investigating the theoretical ideas on affection- and status-related stressors as elaborated in this study. Therefore, we faced some restrictions in the operationalization of especially the status-related stressors. For example, status-related stress could also emerge in other important achievement domains, such as sports. Nevertheless, we believe that the indicators of social stressors that were distilled from the measures as described, come close to the conceptual basis, as we explained in the introduction. The affection-related 
stressors come close to negative experiences in various relationships that generally provide affection (i.e., parents, siblings, partners/spouses). The status-related stressors come close to negative experiences in the domains of school and work, which are indicative of status-related stress for most people.

\section{Affection-and status-related stressors in the last year}

Since the experience of recent affection-related stress or recent status-related stress could influence the reporting of health problems, and perhaps also the reporting of stress in the first half of life, we controlled for recently experienced stress. Concretely, this means that we included the answers on the questions about affection- and status-related stress that were possibly encountered in the past year.

For affection-related stress the following questions were asked: "Has a parent, child, brother, sister or partner died in the last year?"; "Did you and your partner separate during the last year?"; "Did you have difficulties in your partner relation (e.g., jealousy, conflicts, doubts, quarrel) during the last year?"; "Did you have difficulties with your parents (e.g., conflicts regularly, non-acceptance) during the last year?"; "Did you have difficulties in the relationship with your children (e.g., conflicts regularly, little respect from children) during the last year?".

For status-related stress during the last year, the following questions were asked: "Did you became jobless and not succeed in finding work again during the last year?"; "How stressful was your work (e.g., conflicts, too demanding, threat of dismissal) during the last year?". The calculation of the total amount of affection-related stress and total status-related stress in the last year has been done in the same way as in the other stress questions.

\section{Results}

We first inspected possible gender differences in the present sample. Table 1 shows all descriptive values of the variables used in this study, for men and women separately.

Significant differences were found on age, men being somewhat older on average than women; on mean number of chronic diseases, women reporting on average more chronic diseases than men; on mean level of psychological distress (GHQ), women reporting higher levels of distress than men. Regarding affection- and status-related stress before the age of 40, women reporting higher levels of total affection-related stress than men, whereas men reported higher levels of total status-related stress than women. No significant gender differences were found on levels of affection- and status-related stress encountered in the last 12 months.

Next, we tested the two hypotheses. First, it was expected that affection-related stressors encountered in the first half of life would be associated with more chronic diseases and more psychological distress later on, for both men and women. So, no interaction with gender was expected for affection-related stress. Secondly, and contrary to affectionrelated stress, we expected a gender interaction for statusrelated stress, referring to that men will have higher levels of chronic diseases and psychological distress than women, the more status-related stress they have encountered before the age of 40 . In Table 2, the results of the test of these two

Table 1 Descriptives of all study variables $(N=960)$

\begin{tabular}{|c|c|c|c|c|c|c|c|c|c|c|c|}
\hline & \multicolumn{7}{|c|}{ Correlations } & \multicolumn{2}{|l|}{ Mean $(S D)$} & \multirow{2}{*}{$\begin{array}{l}\text { Difference } \\
t \text { test }\end{array}$} & \multirow[t]{2}{*}{$P$} \\
\hline & 1 & 2 & 3 & 4 & 5 & 6 & 7 & $\begin{array}{l}\text { Men } \\
(N=446)\end{array}$ & $\begin{array}{l}\text { Women } \\
(N=514)\end{array}$ & & \\
\hline 1 Age & & $0.30 * *$ & $-0.14 * *$ & $-0.31 * *$ & $-0.25 * *$ & $-0.16^{* *}$ & $-0.41 * *$ & $56.14(10.30)$ & $54.79(9.96)$ & 2.06 & 0.04 \\
\hline $\begin{array}{l}2 \text { Number of chronic } \\
\text { diseases }\end{array}$ & $0.32 * *$ & & $0.18 * *$ & 0.03 & $0.09 *$ & -0.03 & $-0.12 *$ & $0.87(1.15)$ & $1.27(1.55)$ & -4.49 & $<0.001$ \\
\hline $\begin{array}{l}3 \text { Psychological } \\
\text { distress }\end{array}$ & 0.05 & $0.23 * *$ & & $0.23 * *$ & $0.20 * *$ & $0.18 * *$ & $0.23 * *$ & $0.90(0.46)$ & $0.97(0.50)$ & -2.07 & 0.04 \\
\hline $\begin{array}{l}4 \text { Affection-related } \\
\text { stress till } 40\end{array}$ & $-0.40 * *$ & -0.01 & $0.17 * *$ & & $0.36 * *$ & $0.14 * *$ & $0.16^{* *}$ & $0.19(0.21)$ & $0.27(0.21)$ & -5.94 & $<0.001$ \\
\hline $\begin{array}{l}5 \text { Status-related } \\
\text { stress till } 40\end{array}$ & $-0.31 * *$ & $-0.10^{*}$ & -0.02 & $0.39 * *$ & & $0.11 *$ & $0.15^{* *}$ & $0.22(0.24)$ & $0.18(0.23)$ & 2.49 & 0.01 \\
\hline $\begin{array}{l}6 \text { Affection-related } \\
\text { stress last year }\end{array}$ & $-0.22 * *$ & -0.03 & $0.22 * *$ & $0.30 * *$ & $0.15 * *$ & & $0.19 * *$ & $0.08(0.14)$ & $0.10(0.15)$ & -1.70 & 0.09 \\
\hline $\begin{array}{l}7 \text { Status-related } \\
\text { stress last year }\end{array}$ & $-0.38 * *$ & $-0.09 *$ & $0.11 *$ & $0.29 * *$ & $0.22 * *$ & $0.20 * *$ & & $0.13(0.23)$ & $0.13(0.22)$ & -0.23 & 0.82 \\
\hline
\end{tabular}

Women's correlation coefficients are printed below the diagonal, men's above the diagonal

$* P<0.05$; ** $P<0.01$ 
Table 2 Main and moderating effects of affection- and status-related stress and gender on number of chronic diseases and on psychological distress $(N=960)$

\begin{tabular}{|c|c|c|c|c|}
\hline & \multicolumn{2}{|c|}{ Chronic diseases } & \multicolumn{2}{|c|}{ Psychological distress } \\
\hline & Step 1 & Step 2 & Step 1 & Step 2 \\
\hline 1. Age & $0.36^{* * *}$ & $0.36^{* * *}$ & $0.10 * *$ & $0.10 * *$ \\
\hline Gender (1 = women $)$ & $0.15 * * *$ & $0.15^{* * *}$ & 0.03 & 0.03 \\
\hline Affection-related stress last year & 0.01 & 0.01 & $0.16^{* * *}$ & $0.16^{* * *}$ \\
\hline Status-related stress last year & 0.01 & 0.01 & $0.13 * * *$ & $0.14 * * *$ \\
\hline Total affection-related stress till 40 & $0.12 * * *$ & $0.12 * * *$ & $0.16^{* * *}$ & $0.17 * * *$ \\
\hline Total status-related stress till 40 & 0.03 & 0.04 & 0.01 & 0.01 \\
\hline 2. Affection- $*$ status-related stress till 40 & & -0.02 & & -0.01 \\
\hline Affection-related stress till $40 *$ gender & & 0.03 & & -0.003 \\
\hline Status-related stress till $40 *$ gender & & $-0.09 * *$ & & $-0.11 * *$ \\
\hline$R^{2}$ & 0.131 & 0.139 & 0.084 & 0.096 \\
\hline$\Delta R^{2}$ & & 0.009 & & 0.013 \\
\hline Model $F$ & $23.86^{* * * *}$ & $17.10 * * *$ & $14.55 * * *$ & $11.27 * * *$ \\
\hline
\end{tabular}

Standardized coefficients are shown

** $P<0.01 ; * * * P<0.001$

expectations are shown. In all analyses, one-tailed tests are being used, because we test directional hypotheses. Twotailed tests will be reported when the direction of the effects are opposite of the hypothesis.

In two regression analyses-one with chronic diseases as the dependent variable and one with psychological distress as the dependent variable-we tested the effects of affection-related stress and status-related stress, and the interaction of both types of stress with gender. We controlled for the effects of age and the effects of recently (i.e., in the last year) experienced affection-related stress and status-related stress. The latter is important because recently experienced stress may affect the measurement of, especially, psychological distress. All relevant variables were mean centered, in accordance with the recommendations of Aiken and West (1991).

Results showed significant main associations of affection-related stress with both the number of chronic diseases ( $\beta=0.12, P<0.001)$ and the level of psychological distress $(\beta=0.16, P<0.001)$, but no significant main associations for status-related stress $(\beta=0.03$, ns, and $\beta=0.01$, ns, for chronic diseases and psychological distress, respectively). After having included the two-way interactions of affection-related stress by gender and statusrelated stress by gender in the second step, results showed no significant interaction for affection-related stress $(\beta=$ 0.03 , ns, and $\beta=-0.003$, ns, for chronic diseases and psychological distress, respectively), but there is for statusrelated stress $(\beta=-0.09, \quad P<0.01$, and $\beta=-0.11$, $P<0.01$, respectively). This indicates that status-related stress is associated with men's physical and mental health, not with women's health. Affection-related stress, however, seems to be associated with men's and women's health equally.

To decompose and probe the expected lack of a gender interaction for affection-related stress, and the expected presence of a gender interaction for status-related stress, we used simple slope analysis (Aiken and West 1991; Cohen and Cohen 1983). Figures $1 \mathrm{a}, \mathrm{b}$ (affection) and 2a, b (status) show the results, for chronic diseases and psychological distress separately.

The results indicated that, for both men and women, higher levels of affection-related stress were associated with more chronic diseases $\left(B_{\text {men }}=0.46, P<0.05\right.$; $\left.B_{\text {women }}=0.70, P<0.001\right)$ and more distress $\left(B_{\text {men }}=0.80\right.$, $\left.P<0.001 ; B_{\text {women }}=0.77, P<0.001\right)$ than lower levels of affection-related stress.

The results for status-related stress indicated that for men, as expected, higher levels of status-related stress were associated with more chronic diseases $\left(B_{\text {men }}=0.56, P<0.01\right)$ and more distress $\left(B_{\text {men }}=0.51, P<0.01\right)$ than lower levels of status-related stress. For women, as expected, no significant positive associations were found. Interestingly, for chronic diseases $\left(B_{\text {women }}=-0.25, P=0.24\right.$, two-tailed) and for distress ( $B_{\text {women }}=-0.42, P<0.10$, two-tailed) the associations with status-related stress — although not significant-were opposite to what was expected.

\section{Discussion}

Social stressors encountered in the first half of life (from birth on till the age of 40) were found to be associated with 

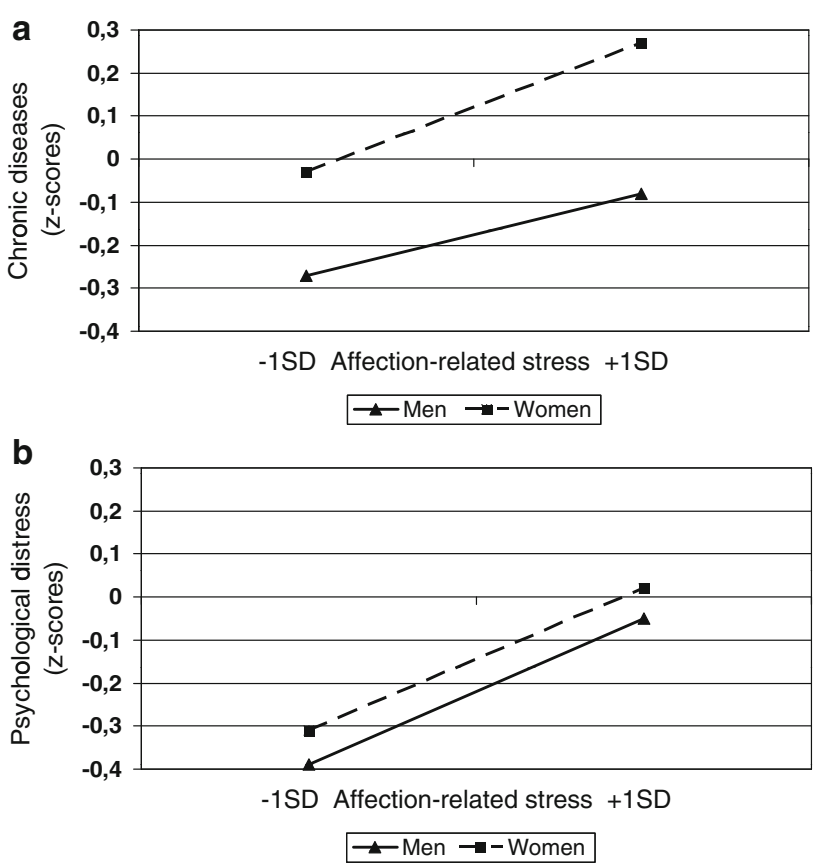

Fig. 1 Graphical presentation of the (lack of) interaction of gender, affection-related stress, and number of chronic diseases (a), and level of psychological distress (b)
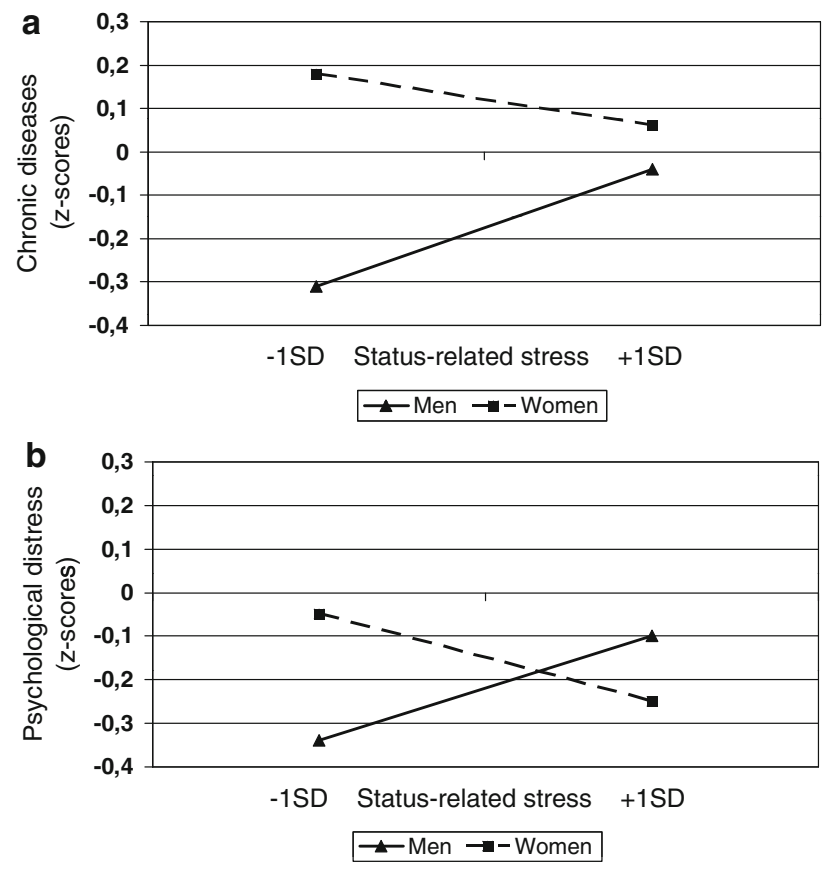

Fig. 2 Graphical presentation of the interaction of gender, statusrelated stress, and number of chronic diseases (a), and level of psychological distress (b)

physical and mental health problems later on, but somewhat differently for men and women. Affection-related stressors were associated with physical and mental health problems for both men and women. In contrast, status-related stressors were associated with physical and mental health problems for men only, not for women. These findings are in line with what was expected on the basis of our theoretical ideas about basic social needsaffection and status needs-in combination with the female advantage in possibilities for substitution regarding statusrelated stress. As such, the findings may add to the existing equivocal state of the art on gender differences in the associations between social stressors and health outcomes. Especially, the finding that affection-related stress was found to be as detrimental to men's health as it was to women's health supports the idea that men also have a basic need for affection, and thus suffer from affectionrelated stress. This finding, therefore, does deviate in part from studies that suggest a gender-dichotomy: that affection-related stress is especially related to women's mental and physiological responses, whereas men-as opposed to women-react most to status-related stress (e.g., Oldehinkel et al. 2007; Stroud et al. 2002). Our findings, instead, are in line with studies that show that the need for belongingness and affection is a general human social need, important to both women and men (e.g., Baumeister \& Leary 1995; Pendell 2002). These findings also seem in line with the strong health effects of both marriage and divorce, especially for men (House et al. 1988; KiecoltGlaser and Newton 2001), which, in our view, refer, at least in part, to the importance of affection need fulfillment for men too.

The findings regarding status-related stress support our hypothesis that women suffer less from status-related stress than men. We expected this to be so, on the basis of the hypothesis that-although both men and women have a need for status - women are better able to substitute status loss by 'producing' more affection. This idea is in line with studies that have shown that, indeed, women are better hardwired for giving and receiving affection than men (e.g., Taylor et al. 2002). Our findings, therefore, suggest that-as SPF theory presumes-the need for status is a basic human social need, for both men and women, as is the need for affection. This is in line with studies that show that both men and women indeed do care for status. For example, it has been suggested that there are no genderspecific social needs, but men and women 'produce' their need fulfillment in different social spheres (Baumeister and Sommer 1997; Gabriel and Gardner 1999). Men would fulfill their social needs primarily in larger groups (collectivistic sphere), women in smaller or dyadic groups (relational sphere). Gender differences in need fulfillment (or lack of fulfillment) are thus not laid in gender-specific social needs, but in the different social spheres. On the basis of our data, we cannot distinguish between social spheres, but it may be an important additional aspect of the explanation of gender differences. Moreover, women (with 
a male partner) may suffer less from status-related stress than men, because they probably can substitute status loss by focusing more on the status of their male spouse. The negative association between status-related stress and later distress for women, although not significant, may also point to this possibility. Moreover, we cannot rule out that women, who have suffered status-related stress before the age of 40, later may have withdrawn from work to focus on their family and children (i.e., affection). This may then explain why they report less, rather than more distress after having encountered status-related stress. For men, this substitution possibility is much less an option, at least in the Netherlands. Finally, we also cannot rule out that men may still be more reactive (physiologically) to statusrelated stress than women. Further research is needed to solve these remaining puzzles and examine alternative explanations.

Our study also has its limitations. First, the genderspecific substitution argument could only be tested indirectly, because we did not have data on concrete substitution actions. Although earlier studies have supported the presupposed substitution patterns (e.g., Steverink and Lindenberg 2006), future research should test the substitution argument in a more direct way. This can be done by, for example, assessing how people 'produce' affection and status over time, and how the loss of resources for status may lead to increases in the use of resources for affection.

Second, the cross-sectional data of our study are problematic for inferences about the presumed causal mechanisms. For this, longitudinal data are needed. Nevertheless, because the data allowed us to separate the experiences of social stressors (before age of 40) from the health outcomes later on (after the age of 40), we more or less had two measurement moments, approaching a longitudinal design. Still, longitudinal data are needed to get more robust evidence.

Third, in this study we investigated the overall impact of affection- and status-related stressors, encountered in the first half of life, and health outcomes later on (in the second half of life). On the basis of SPF theory, no hypotheses could be formulated on more specific developmental processes or causes and effects. Still, in order to explore the possibility of developmental issues, we checked in a post hoc analysis, whether the three available life periods (in the data: age 0-12, age 13-18, and age 19-39), were related differentially to health effects. Regression analyses, containing the social stressors in the separate life periods as predictors, showed no significant associations with health outcomes. This indicates that our data did not show that, having encountered affection- or status-related stress in one of the three life periods, is significantly related to health later on. However, our results showed that, when men and women had encountered affection-related stress in all three life periods (till the age of 40), this was significantly related to mental and physical health later on. In additionally, men who had encountered status-related stress in all three life periods showed to have a significantly worse mental health later on; when they had encountered status-related stress in the first two age periods (0-12 and 13-18), they showed a significantly worse physical health. In conclusion, our data did not show specific effects for separate developmental phases, but they provided evidence, as we hypothesized, of the association between social stress encountered in the first half of life and health problems later on. Notwithstanding this finding here, future research might focus on possible developmental processes in the link between social stress and health problems later on. However, then also clear developmental theory is needed, and possibly also more detailed information on specific social stressors.

Fourth, the main independent variables-social stressors encountered before the age of 40-were self-reported, and measured retrospectively. This brings the risk of subjectivity and memory biases, which may cause the data to be unreliable. Nevertheless, because the social stressors were all measured as events rather than as feelings, these risks may again be limited. People, in general, report more reliably on events than on feelings, and they also can remember events more reliably than feelings. Furthermore, we took recently experienced stress into account. In that way, we filtered out bias due to stress experienced in the past year. Nevertheless, in future research this should be taken into consideration and more objective measures should be added.

Finally, the measurement of the health outcomes was also measured by self-report, which has the same risk of subjectivity or memory biases as have the social stressors. Future studies should include both objective and subjective measures of health in order to get more insight in objective versus subjective health problems.

These limitations not withstanding, this study has contributed to the knowledge on the gender issue in the link between social stress and health. More precisely, it indicates that status-related stressors encountered in the first half of life may undermine the later-life physical and mental health of men, not women. However, affectionrelated stressors seem to harm the later-life physical and mental health of both men and women, not only of women as is often assumed. This knowledge may have important implications for social interventions in preventive public health.

Open Access This article is distributed under the terms of the Creative Commons Attribution Noncommercial License which permits any noncommercial use, distribution, and reproduction in any medium, provided the original author(s) and source are credited. 


\section{References}

Aiken LS, West SG (1991) Multiple regression: testing and interpreting interactions. Sage, London

Artazcoz L, Benach J, Borrell C, Cortès I (2004) Umemployment and mental health: understanding the interactions among gender, family roles, and social class. Am J Public Health 94:82-88

Baumeister RF, Leary MR (1995) The need to belong: desire for interpersonal attachments as a fundamental human motivation. Psych Bull 117:497-529

Baumeister RF, Sommer KL (1997) What do men want? Gender differences and two spheres of belongingness: comment on Cross and Madson (1997). Psych Bull 122:38-44

Bruggink JW, Knoops K, Nusselder WJ, van Gool CH (2010) De gezonde levensverwachting samengevat. In Volksgezondheid Toekomst Verkenning, Nationaal Kompas Volksgezondheid. RIVM, Bilthoven

Brugha TS, Cragg D (1990) The list of threatening experiences: the reliability and validity of a brief life events questionnaire. Acta Psychiatr Scand 82:77-81

Cacioppo JT, Hughes ME, Waite LJ, Hawkley LC, Thisted RA (2006) Loneliness as a specific risk factor for depressive symptoms: crosssectional and longitudinal analyses. Psychol Aging 21:140-151

Cohen J, Cohen P (1983) Applied multiple regression/correlation analyses for the behavioral sciences, 2nd edn. Lawrence Erlbaum, Hillsdale

Cohen S, Frank E, Doyle WJ, Skoner DP, Rabin BS, Gwaltney JM Jr (1998) Types of stressors that increase susceptibility to the common cold in healthy adults. Health Psychol 17:214-223

Cohen S, Alper CM, Doyle WJ, Adler N, Treanor JJ, Turner RB (2008) Objective and subjective socioeconomic status and susceptibility to the common cold. Health Psychol 27:268-274

Cross SE, Madson L (1997) Models of the self: self-construals and gender. Psychol Bull 122:5-37

Cyranowski JM, Frank E, Young E, Shear K (2000) Adolescent onset of gender differences in lifetime rates of major depression. A theoretical model. Arch Gen Psychiatr 57:21-27

Deci EL, Ryan RM (2000) The "what" and "why" of goal pursuits: Human needs and the self-determination of behavior. Psychol Inquiry 11:227-268

Denton M, Prus S, Walters V (2004) Gender differences in health: a Canadian study of the psychosocial, structural and behavioural determinants of health. Soc Sc Med 58:2585-2600

Gabriel S, Gardner WL (1999) Are there "his" and "hers" types of interdependence? The implications of gender differences in collective versus relational interdependence for affect, behavior, and cognition. J Pers Soc Psychol 77:642-655

Gordon LV (1949) The reflection of problem changes by the Mooney Problem Checklist. Educ Psychol Measurement 9:749-752

Hammarström A, Janlert U (2002) Early unemployment can contribute to adult health problems: results from a longitudinal study of school leavers. J Epidemiol Community Health 56:624-630

Hawkley LC, Thisted RA, Masi CM, Cacioppo JT (2010) Loneliness predicts increased blood pressure: 5-year cross-lagged analyses in middle-aged and older adults. Psychol Aging 25:132-141

House JS, Landis KR, Umberson D (1988) Social relationships and health. Science 241:540-545

Kiecolt-Glaser JK, Newton TL (2001) Marriage and health: his and hers. Psychol Bull 127:472-503

Kiecolt-Glaser JK, Newton T, Cacioppo JT, MacCallum RC, Glaser R, Malarkey WB (1996) Marital conflict and endocrine function: are men really more physiologically affected than women? J Consult Clin Psychol 64:324-332

Kiecolt-Glaser JK, Loving TJ, Stowell JR, Malarkey WB, Lemeshow S, Dickinson SL, Glaser R (2005) Hostile marital interactions, proinflammatory cytokine production, and wound healing. Arch Gen Psychiat 62:1377-1384

Koeter MW (1992) Validity of the GHQ and SCL anxiety and depression scales: a comparative study. J Affect Disord 24: 271-279

Levenson RW, Carstensen LL, Gottman JM (1994) The influence of age and gender on affect, physiology, and their interrelations: a study of long-term marriages. J Pers Soc Psychol 67:56-68

Lindenberg S (1996) Continuities in the theory of social production functions. In Lindenberg SM, Ganzeboom HBG (eds) Verklarende sociologie: opstellen voor Reinhard Wippler [Explanatory sociology: Essays in honor of Reinhard Wippler]. Thesis, Amsterdam, pp 169-184

Litwin H (2007) What really matters in the social network-mortality association? A multivariate examination among older JewishIsraelis. Eur J Ageing 4:71-82

Luecken LJ, Appelhans BM, Kraft M, Brown A (2006) Never far from home: a cognitive-affective model of the impact of earlylife family relationships on physiological stress responses in adulthood. J Soc Pers Relationsh 23:189-203

Maccoby EE (1990) Gender and relationships: a developmental account. Am Psychol 45:513-520

McDonough P, Walters V (2001) Gender and health: reassessing patterns and explanations. Soc Sc Med 52:547-559

Newson JT, Mahan TL, Rook KS, Krause N (2008) Stable negative social exchanges and health. Health Psychol 27:78-86

Nieboer A, Lindenberg S (2002) Substitution, buffers and subjective well-being: a hierarchical approach. In: Gullone E, Cummins RA (eds) The universality of subjective well-being indicators. Kluwer Academic Publishers, Dordrecht, pp 175-189

Oksuzyan A, Brønnum-Hansen H, Jeune B (2010). Gender gap in health expectancy. Eur J Ageing 7(4). doi:10.1007/s10433-0100170-4

Oldehinkel AJ, Rosmalen JGM, Veenstra R, Dijkstra JK, Ormel J (2007) Being admired or being liked: classroom social status and depressive problems in early adolescent girls and boys. J Abnormal Child Psychol 35:417-427

Ormel J, Lindenberg S, Steverink N, Verbrugge LM (1999) Subjective wellbeing and social production functions. Soc Indicat Res 46:61-90

Pendell SD (2002) Affection in interpersonal relationships: not just "a fond or tender feeling". Commun Yearb 26:70-115

Pinto-Sietsma SJ, Janssen WMT, Hillege HL, Navis G, de Zeeuw D, De Jong PE (2000) Urinary albumin excretion is associated with renal functional abnormalities in a nondiabetic population. J Am Soc Nephrol 11:1882-1888

Repetti RL, Taylor SE, Seeman TE (2002) Risky families: family social environments and the mental and physical health of offspring. Psychol Bull 128:330-366

Seeman TE (1996) Social ties and health: the benefits of social integration. Ann Epidemiol 6:442-451

Steverink N (2001) When and why frail elderly people give up independent living: The Netherlands as an example. Ageing Soc 21:45-69

Steverink N, Lindenberg S (2006) Which social needs are important for subjective well-being? What happens to them with aging? Psychol Aging 21:281-290

Steverink N, Lindenberg S, Ormel J (1998) Towards understanding successful ageing: patterned change in resources and goals. Ageing Soc 18:441-467

Stroud LR, Salovey P, Epel ES (2002) Sex differences in stress responses: social rejection versus achievement stress. Biol Psychiat 52:318-327

Taylor SE, Dickerson SS, Cousino Klein L (2002) Toward a biology of social support. In: Snyder CR, Lopez SJ (eds) Handbook 
of positive psychology. Oxford University Press, Oxford, pp 556-569

Tiffin PA, Pearce MS, Parker L (2005) Social mobility over the lifecourse and self reported mental health at age 50: prospective cohort study. J Epidemiol Community Health 9:870-872

Uchino BN, Cacioppo JT, Kiecolt-Glaser JK (1996) The relationship between social support and physiological processes: a review with emphasis on underlying mechanisms and implications for health. Psychol Bull 119:488-531

Umberson D, Chen MD, House JS, Hopkins K, Slaten E (1996) The effect of social relationships on psychological well-being: are men and women really so different? Am Sociol Rev 61:837-857

Vermeulen M, Mustard C (2000) Gender differences in job strain, social support at work, and psychological distress. J Occup Health Psychol 5:428-440 